\title{
Improvement of the Optical Performance of the Geometrical Parameters of Snorkel Magnetic Lens
}

\author{
*Marwa T. Al-Shamma \\ Muna A. Al-Khashab \\ Department of Physics/ College of Science/ University of Mosul
}

*E-mail: Marwathamer82@yahoo.com

(Received 13/6/2018; Accepted 17/9/2018)

\begin{abstract}
Two models of asymmetrical magnetic objective lens geometries have been designed and studied. These two models are called Pinhole and Snorkel lenses. The comparison between these models was realized by the aid of simulation EOD program (Electron Optical Design), using the finite element method to analyze the magnetic flux density and optical properties at constant excitation $(\mathrm{NI}=2000 \mathrm{~A}-\mathrm{t})$. The optimal model (Snorkel Lens) gives the best characteristics that were compatible with the research purposes in details, such as the changing of air gap and the axial polepiece bore diameter on the optical performance of the snorkel magnetic lens. This type of lens was used in low energies scanning electron microscope (SEM), which achieved the lowest values of the aberrations coefficient at long working distance.
\end{abstract}

Keywords: Asymmetrical objective magnetic lens design, Snorkel magnetic lens, Pinhole magnetic lens, Single polepiece magnetic lens.

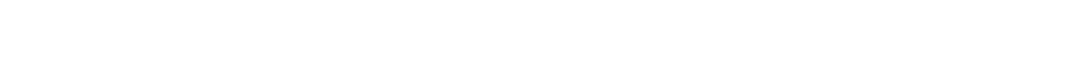

\begin{abstract}
الملهص
مُ تصميم ودرلسة نمونجين من العهلت المغنلطيسية للثيئية اللامتنظارة، النموذج الأول يسم عهية الثب (Pinhole lens) والمعروف بأسم (EOD) والذي يستخدمطريقة العناصر المحدوة، لتحليل كثلفة الفيض المغنلطيسي والخواص البصرية عند تهبج ثابت (NI = 2000 A-t). مُ درلسة النموذج الأمثل (عهسةسنوركل) الذي هقق أفضل الخواص المتوافة مع أغراض البهث بالفصل، كتغيير الفجوة الهوائية فضلا عن قطر الفتحة المحورية للنطب على الأداء البصري للعهسة المغنطيسية. بستخدم هذا

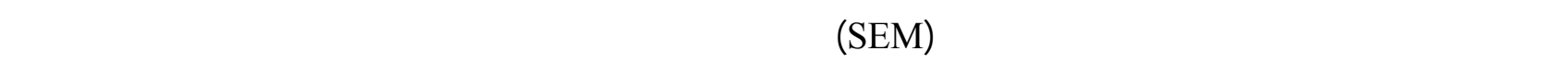
مسافة تشغيل لمديلت ولسعة.
\end{abstract}

الكاملت الدالة: تصميم العهسة المغنليسية الثيئية اللامتنظرة، عهسةسنوركل المغنلطيسية، عهة القب المغنطيسية، العهسة المغنلطيسية لحادية القطب.

INTRODUCTION

In many electron beam probe instruments, such as scanning electron microscopes and scanning electron beam lithography systems, a divergent ray of electron beam emitted from the electron cathode 
or field emission tip is focused on to a small spot using cascade demagnifying magnetic lenses, which produces an axially symmetrical field distribution in the space. One of these lenses at the final of the column is called the objective lens and this lens is very important that determines the final diameter of the electron probe, if the performance of the objective lens is not good an optimally fine electron probe cannot be produced despite all of the efforts before the action of the objective lens. Thus, it is crucial to make the objective lens with the best performance.

There are three basic designs of objective lens: the first is called pinhole or conical lens, where the specimen is outside the lens and its magnetic field; the second has specimens small enough (just several $\mathrm{mm}$ ) to be placed inside the lens which is called immersion lens, while the third one is a snorkel lens, where the specimen is outside the lens but inside its magnetic field (Goldstein et al., 2003).

The single polepiece lens (snorkel lens) was firstly proposed by Mulvey in 1973 (Mulvey and Newman, 1973). This lens has many advantages in low-voltage SEM and combines the best features of both the pinhole and the immersion lenses, its magnetic field extends outside the lens and reaches the specimen. Intensive studies have been carried out to optimize the geometric shape with appropriate geometric dimensions of magnetic electron lenses for the symmetrical double polepiece lens by (Cleaver, 1980) and asymmetrical double polepiece lens by (Wenxiong, 1988).

The optimization of the polepiece shape was studied for asymmetrical single polepiece lens by (Al-Khashab and Abbas, 1991). Asymmetrical magnetic lenses in conical shape geometries was designed with a set of asymmetrical two-coaxial overlapping cylinder electrostatic lenses to obtain the compound lenses achieved by Abd-Hujazie (2006), this type of lens used in low energy scanning electron microscope. The magnetization of the single polepiece magnetic electron lens using different coil shapes was investigated by Al-Khashab and Al-Abdullah (2006). Single polepiece lens was manufactured as a compound lens by Al-Jumayli (2010). Al-Khashab and Ahmad (2011), suggested the effect of the structure insulation on optical properties of magnetic single polepiece lens. Also the investigation of pole piece shape for saturated single pole magnetic lens and the effect of the lens size on performance of the single pole magnetic lens was studied by EL-Shahat et al., (2014 (a,b)). Radial gap lens was design and fabricate as objective magnetic lens by Al-Jubbori (2014), with double condenser lens to form illumination system in scanning electron microscope.

The aim of this work is to design two models of asymmetrical magnetic objective lens geometry for scanning electron microscope, the first model is called pinhole lens and the second one is called snorkel lens. Their optical properties are realized by the aid of simulation EOD program (Electron Optical Design), at constant excitation ( $\mathrm{NI}=2000 \mathrm{~A}-\mathrm{t}$ ), then the optimal model was chosen such that to achieve the best properties witch was compatible with the research purposes that have been studied it, such as the changing of air gap and the axial bore diameter on the optical performance of the snorkel magnetic lens.

\section{The Analysis Simulation}

\section{CALCULATIONS AND RESULTS}

Simulation plays a key role in the design and optimization of charged particle optical systems. This enables the performance of such systems to be predicted accurately before built, thereby saving a great deal of time and money (Munro, 2011). This advances in computer simulations help to solve a lot of complicated lenses designs which was impossible to implement previously (Abbass and Nasser, 2012).

The finite element method has been used as a numerical technique for drawing the geometrical shapes of the designed magnetic lens and the generation of the triangular finite element meshes for each design. EOD program (Electron Optical Design) version 3.069, built by Lencov'a and Zl'amal (2008) was used to design and evaluate the electron-beam system properties. The software package 
offers a design environment, field calculation, ray tracing, evaluation of paraxial properties and aberrations. The spherical and chromatic aberrations coefficient was calculated by using the following equations respectively (Nakagawa et al., 1980).

$$
\begin{aligned}
& C_{z}=\frac{e}{128 m V_{r}} \int_{z_{0}}^{z_{i}}\left(\frac{3 e}{m V_{r}} B_{z}^{4} R_{\alpha}^{4}(z)+8 B_{z}^{2^{r}} R_{\alpha}^{4}-8 B_{z}^{2} R_{\alpha}^{2}(z) R_{\alpha}^{2^{r}}\right) d z \\
& C_{c}=\frac{e}{8 m V_{r}} \int_{z_{0}}^{z_{i}} B_{z}^{2} R_{\alpha}^{2}(z) d z
\end{aligned}
$$

\section{Design of the Magnetic Objective Lens and Results}

The design of magnetic lenses requires the determination of the best geometric structure of the electrode and their associated operating conditions (operating voltage, excitation, operating mode and focal properties), as well as the suitable shape and size of the coil (Al-Khashab and Al-Hialey, 2013).

Two models of asymmetrical objective magnetic lens have been designed. The first model is called pinhole lens (PL) and the other is called snorkel lens (SL). Fig. (1) shows the diagram and geometrical dimension for the upper half of the two models of the lenses suggested in this work. It seems that the two models are symmetrical in terms of axial length of lens $(140 \mathrm{~mm})$, radial width of lens $(150 \mathrm{~mm})$, polepiece parameters, geometrical structure of the magnetic circuit, coil shape, coil sectional area of $\left(1000 \mathrm{~mm}^{2}\right)$, air gap $(S=9 \mathrm{~mm})$, polepiece snot face $(4 \mathrm{~mm})$ and axial bore diameter of pole $\left(D_{p}=6 \mathrm{~mm}\right)$, except for the shape of the iron shroud. A cylindrical gap of $(20 \mathrm{~mm})$ diameter with about $(65 \mathrm{~mm})$ length has been design in the two models which can be used as a place of the magnetic deflectors for future works.

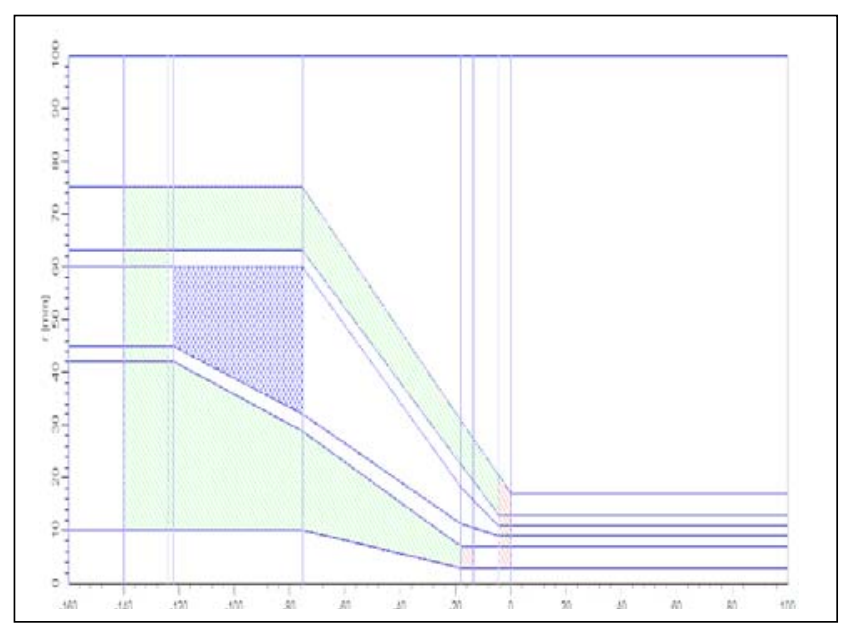

(a)

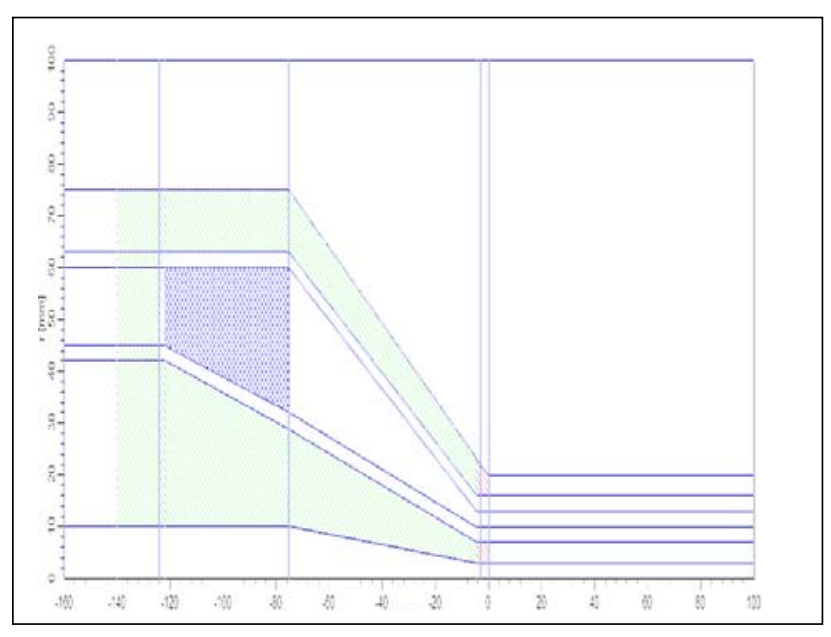

(b)

Fig. 1: Diagram of the geometrical dimensions of upper half for the two models. (a): Pinhole lens (PL), (b): Snorkel lens (SL).

In order to demonstrate the performance of the proposed objective magnetic lenses shown in Fig. (1). The axial magnetic flux density distribution of the two designed lenses was computed by the aid of program (EOD) version 3.069, built by Lencov'a and Zl'amal (2008) using the finite element method. Fig. (2) illustrates the comparison between the axial magnetic flux density distribution for the designed 
lenses as a function of axial distance at the same excitation (NI=2000 A-t). From the figure we observed that the peak of the magnetic flux and the shape of the distribution depends entirely on the geometrical design of the lens. It is evident that the distribution of the magnetic flux density of the lens (PL) is symmetrical of bell-shaped and it has approximately a great value in the middle of air gap, where the specimen is outside the magnetic field in which the aberration coefficient values are expected to be high (Mulvey, 1982). While the distribution of the magnetic flux density of the lens (SL) is asymmetrical and it rises slowly at the edge of the pole and falls rapidly and extends towards the specimen, in this case the specimen is immersed within the magnetic field.

The distribution of the trajectory of magnetic flux lines in the structure of magnetic lenses has a great importance in the study of lens behavior and knowledge of the optical performance of each part in it as well as knowledge of magnetic leakage in their structures. The (EOD) program was used to plot the trajectory of the magnetic flux lines at $(\mathrm{NI}=2000 \mathrm{~A}-\mathrm{t})$. These lines represent the magnetic flux density points at each point of the lens (Hill and Smith, 1980).

Fig. (3) illustrates the flux lines trajectories and color representation of the magnetic flux for the designed lenses in 2D and 3D view. It is seen from this figure that these lines are nearly incident normally at the surface of the pole and become parallel to each other inside the polepiece structure. Also it is noticed that the flux lines are centered within the lens (PL), while these lines extend outside the lens (SL) in front of the specimen.

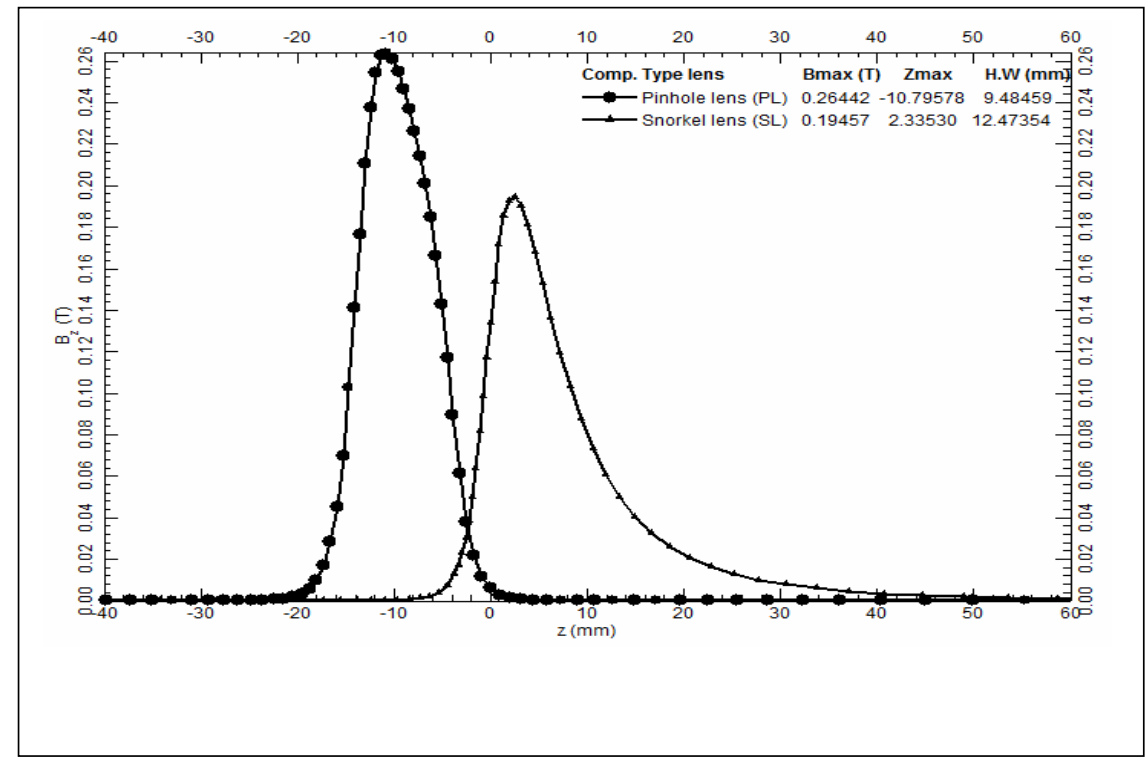

Fig. 2: The axial magnetic flux density distributions $\left(B_{z}\right)$ as a function of the axial distance $(z)$ for the designed lenses at the same excitation $(N I=2000$ A-t).

The optical properties of the proposed lenses were calculated for the appropriate design of the lens in many electron instrument are largely depend on these properties (Mulvey, 1982), this leads to low magnetic lens aberrations coefficient and gives a better image quality with a high resolution.

In order to design an objective magnetic lenses for scanning electron microscope it means that the specimen must be located outside the lens body and at a certain working distance (the distance from the end of the lens to the specimen). 
The optical properties were calculated using a program (EOD), it was found that each design at a certain working distance (W.D.) has a specific relativistic accelerating voltage $\left(\mathrm{V}_{\mathrm{r}}\right)$ as shown in the Fig. (4). It is clear that the lens (SL) has low values of the $\left(\mathrm{V}_{\mathrm{r}}\right)$ compared with the lens (PL). The spherical aberration coefficient $\left(\mathrm{C}_{\mathrm{s}}\right)$ and chromatic aberration coefficient $\left(\mathrm{C}_{\mathrm{c}}\right)$ were calculated as function of working distances the for two design lenses as illustrated in Fig. (5), it is clear that the aberration coefficients are increased by increasing the working distance and the (SL) lens has given a better properties than the (PL) lens, because the specimen is immersed within the field of the (SL) lens while the specimen is outside the field in the (PL) lens.

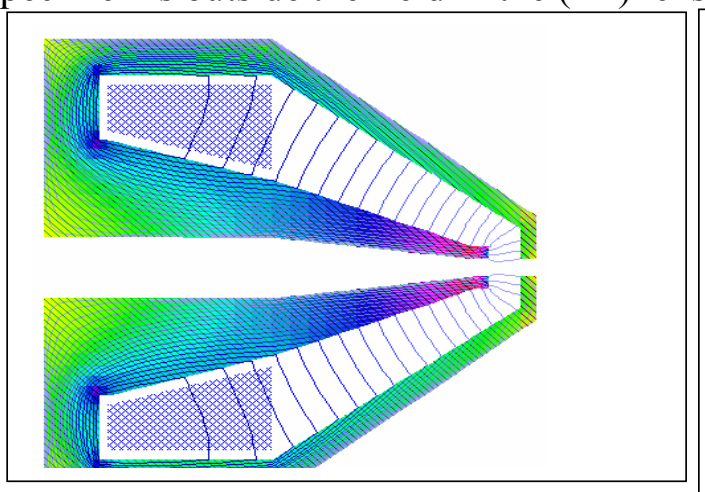

\section{Legend:}

Saturation [T] Magnetic flux [uWb]
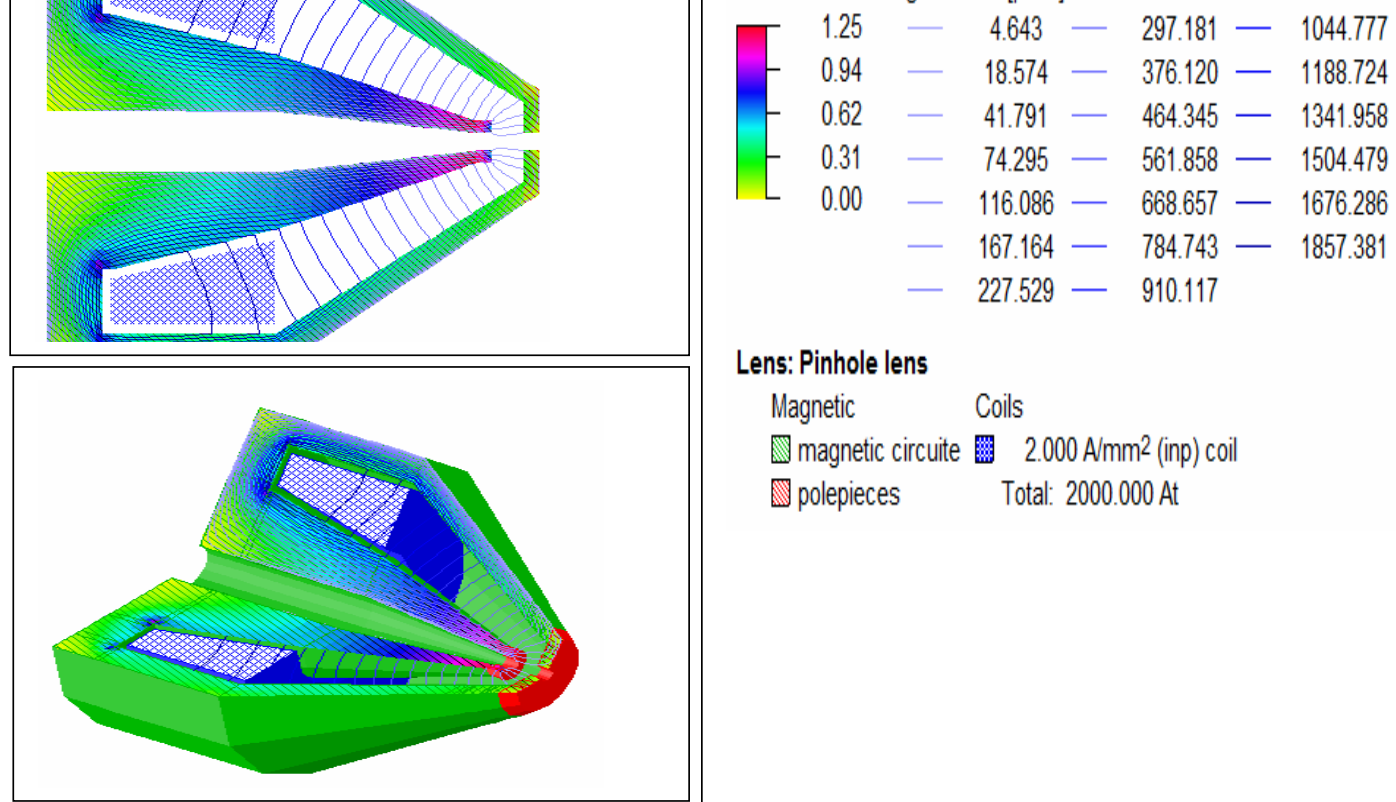

Lens: Pinhole lens

Magnetic Coils

$\mathbb{Q}$ magnetic circuite ․․․ $2.000 \mathrm{~A} / \mathrm{mm}^{2}$ (inp) coil

$\mathbb{Q}$ polepieces $\quad$ Total: 2000.000 At

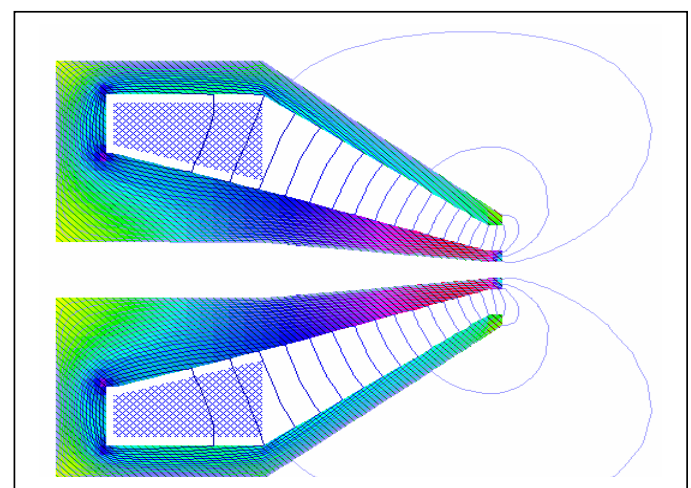

Legend:

Saturation [T] Magnetic flux [uWb]

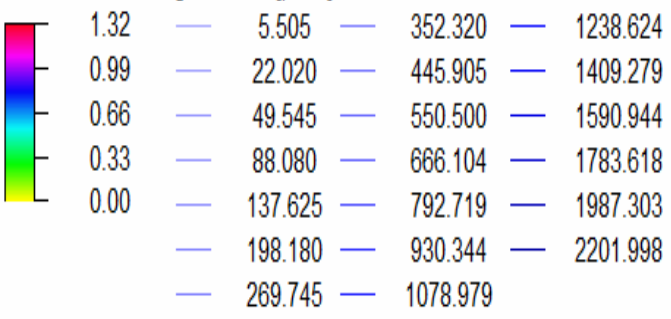

Lens: Snorkel lens

Magnetic Coils

\ magnetic circuite : $1.000 \mathrm{~A} / \mathrm{mm}^{2}$ (inp) coil

$\mathbb{Q}$ polepieces Total: $2000.000 \mathrm{At}$

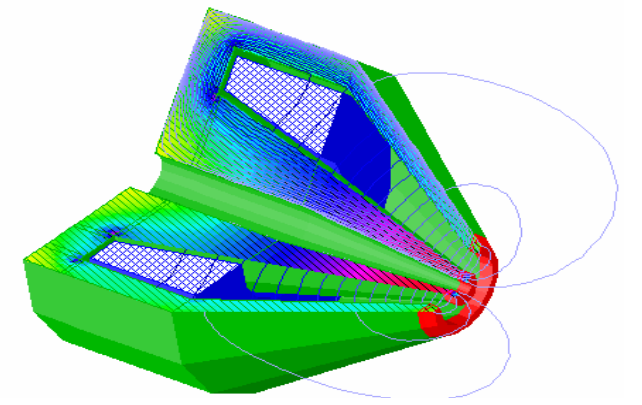

Fig. 3: Flux lines trajectories and color representation of the magnetic flux for the designed lenses in two and three dimensions view 


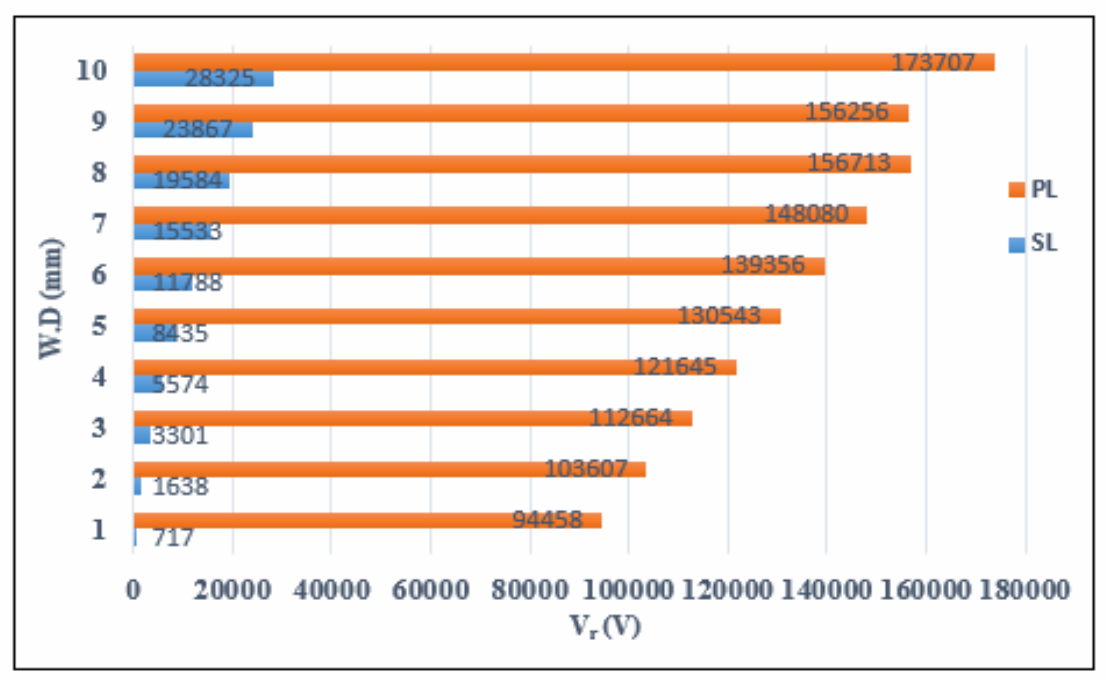

Fig. 4: The relativistic accelerating voltage $\left(V_{r}\right)$ as a function of the working distance (W.D) for the designed lenses
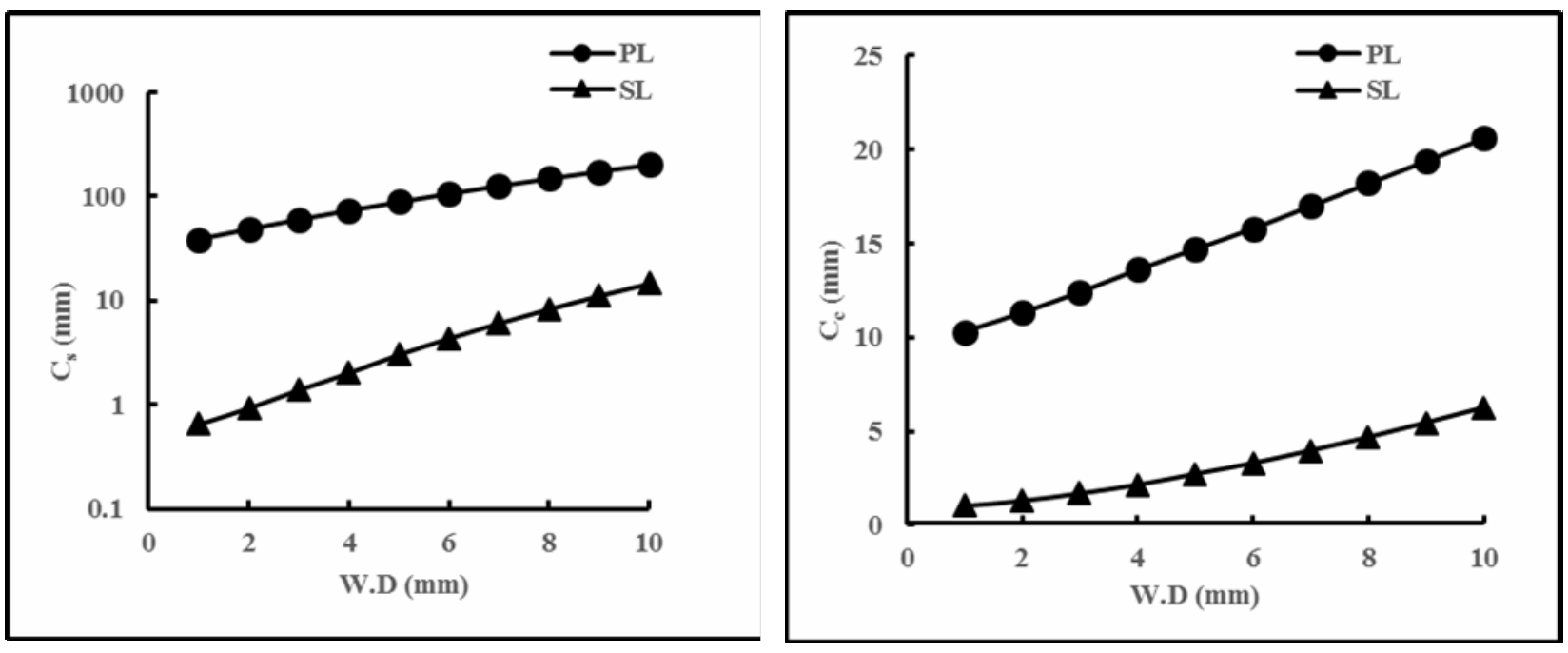

Fig. 5: The variation of the spherical and chromatic aberration coefficients $\left(C_{s}\right.$ and $\left.C_{c}\right)$ as a function of the working distance (W.D) for the designed lenses at constant excitation $(\mathrm{NI}=\mathbf{2 0 0 0}$ A-t).

The resolving power for the each lens design was calculated at a constant excitation $(\mathrm{NI}=2000 \mathrm{~A}-\mathrm{t})$, using the equation $\left[\left(\delta=0.71\left(C_{s}^{1 / 4} \lambda^{3 / 4}\right)\right.\right.$ in $\mathrm{nm}$, where $\lambda$ being the electron wave length. Fig. (6) shows the variations of the resolving power $(\delta)$ and image position $\left(\mathrm{z}_{\mathrm{i}}\right)$ as a function of the relativistic accelerating voltage for the designed lenses at a constant excitation $(\mathrm{NI}=2000$ A.t). For 
the (PL) lens it was observed that $(\delta)$ increases with an increasing of $\left(\mathrm{V}_{\mathrm{r}}\right)$ until it reaches an approximate value $\left(\delta=0.82 \mathrm{~nm}\right.$ at $\left.\mathrm{V}_{\mathrm{r}}=48 \mathrm{KV}\right)$ and then begins to decrease. The increase in $\left(\mathrm{V}_{\mathrm{r}}\right)$ leads to a large increase in the amount of aberration coefficient at long working distance, also it was noticed that the applied accelerating voltages in the (PL) lens within the range (1 KV-85 KV) were focusing the electron beam inside the lens which is incompatible with the purpose of the this work, so it is necessary to increase the accelerating voltages which make the electron beam to be focused out of the lens.

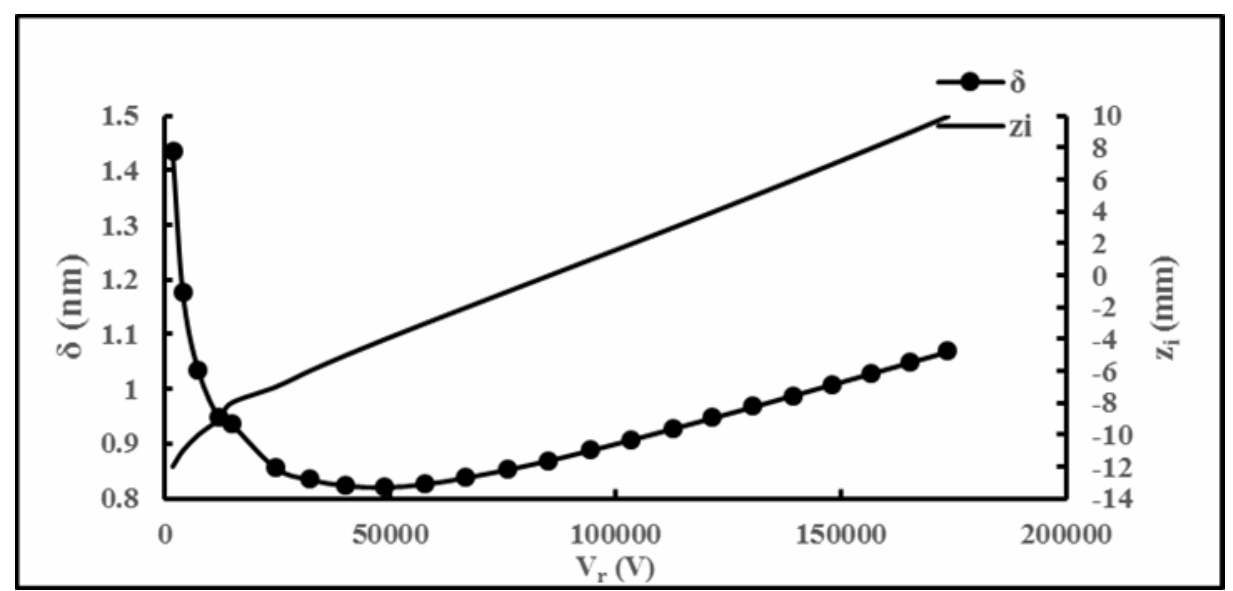

(a)

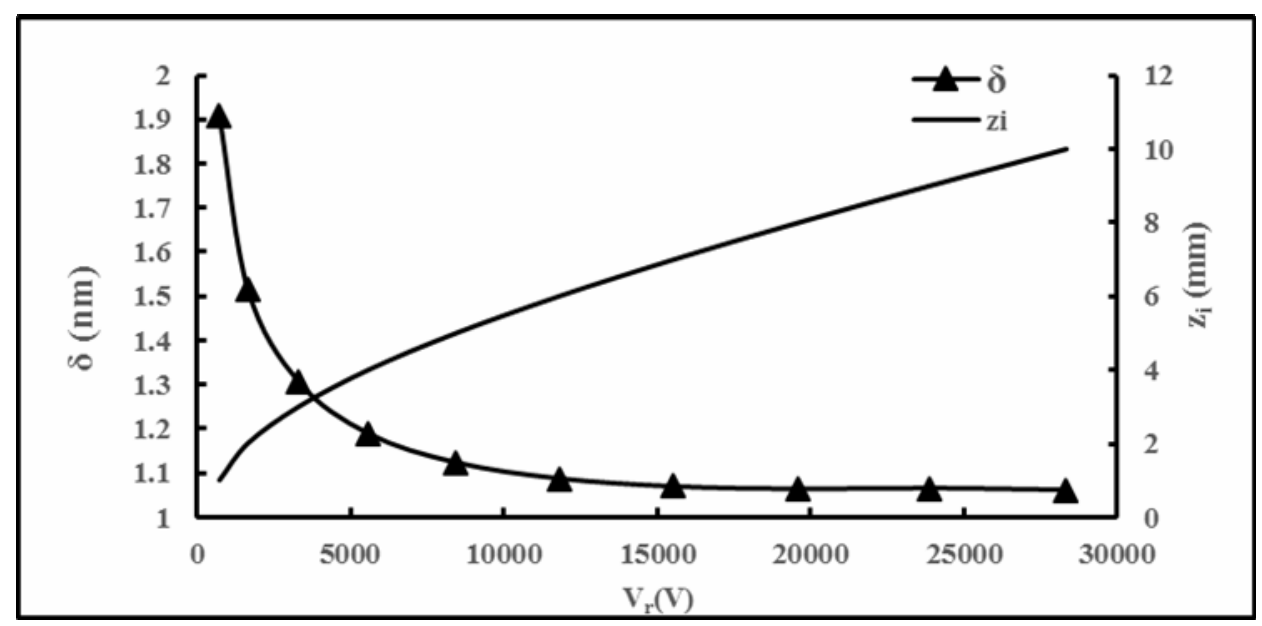

(b)

Fig. 6: The variation of the resolving power $(\delta)$ and image position $\left(z_{i}\right)$ as a function of the relativistic accelerating voltage for the designed lenses at a constant excitation

This work shows that the snorkel (SL) lens has much better properties compared with the pinhole (PL) lens and it suitable for the purposes of the research, therefore it will be studied extensively in the following items. 


\section{The Effect of the Air Gap on the Snorkel Lens Properties}

In order to investigate the effect of the air gap (S) on the optical performance of the snorkel lens, different values of $(\mathrm{S})$, have been chosen, such that $[\mathrm{S}=(3,6,9$ and 12) $\mathrm{mm}]$ keeping the other geometrical parameters constant. Fig. (7) shows the effect of (S) on the axial magnetic flux density distribution $\left(B_{z}\right)$. It is noticed that the maximum value of $\left(B_{z}\right)$ increase as the values of $(\mathrm{S})$ decrease.

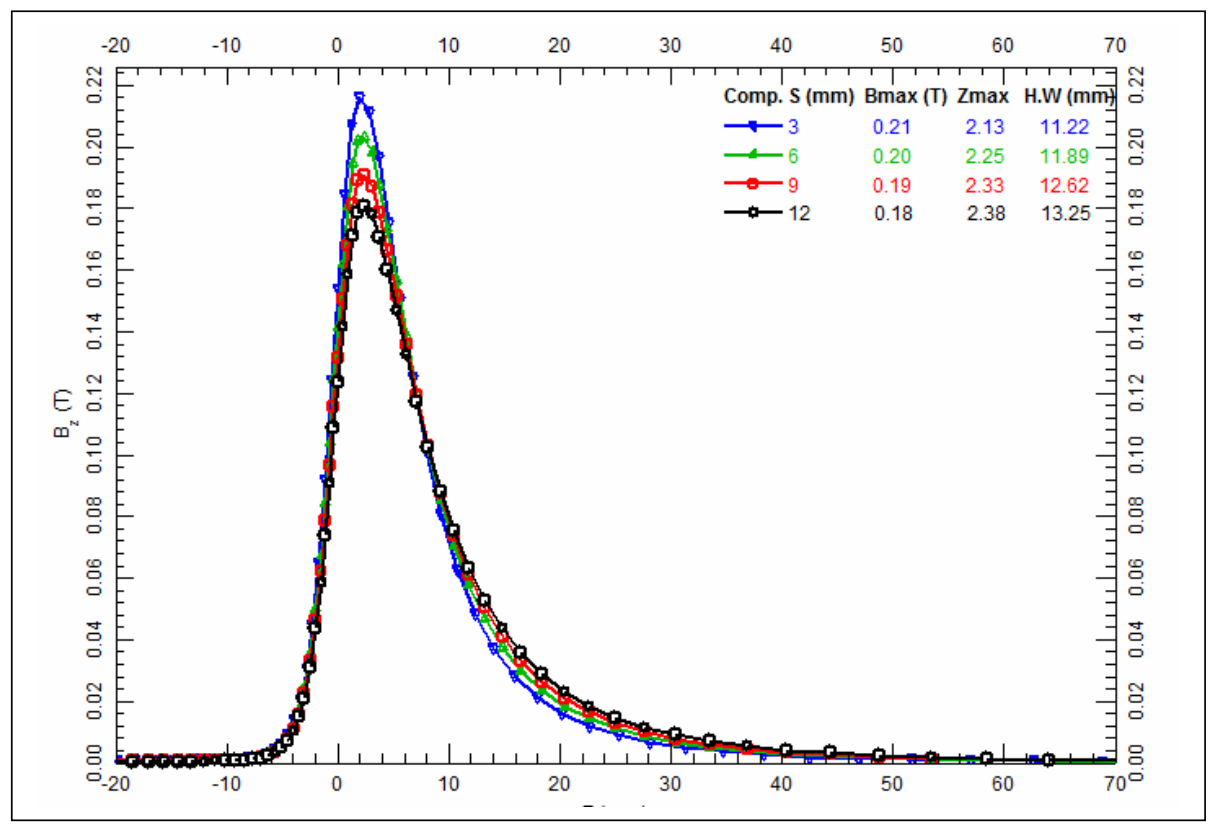

Fig. 7: The axial magnetic flux density distributions $\left(B_{z}\right)$ as a function of the axial distance $(z)$ of (SL) lens for different values of (S) at the same excitation (NI=2000 A-t).

Fig. (8) illustrates the flux lines trajectories for the (SL) lens at different values of (S) with in the same excitation $(\mathrm{NI}=2000 \mathrm{~A}-\mathrm{t})$. It is noticed that these lines are converged and focalized between the poles when the air gap decreases. Fig. (9) shows the variations of the spherical and chromatic aberration coefficients $\left(\mathrm{C}_{\mathrm{s}}\right.$ and $\left.\mathrm{C}_{\mathrm{c}}\right)$ as a function of the relativistic accelerating voltage $\left(\mathrm{V}_{\mathrm{r}}\right)$ of lens $(\mathrm{SL})$ for different values of $(\mathrm{S})$ with in same excitation $(\mathrm{NI}=2000 \mathrm{~A}-\mathrm{t})$, it is clear that the $\left(\mathrm{C}_{\mathrm{s}}\right.$ and $\left.\mathrm{C}_{\mathrm{c}}\right)$ are increased by increasing the $\left(\mathrm{V}_{\mathrm{r}}\right)$ and the lowest values of aberration coefficients were reached when $(\mathrm{S}=3 \mathrm{~mm})$. 

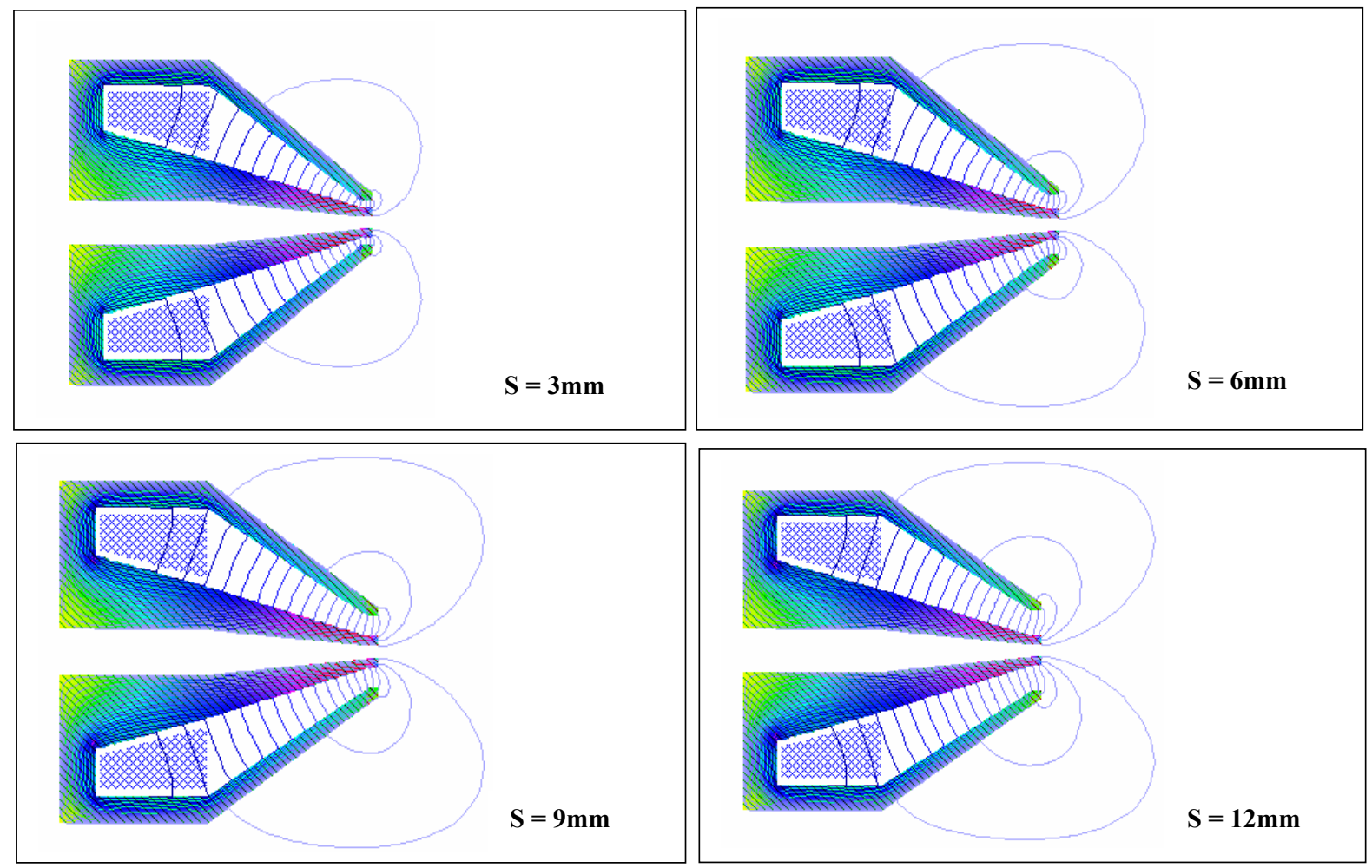

Fig. 8: Flux lines trajectories of (SL) lens for different values of air gap (S) at the same excitation $(\mathrm{NI}=\mathbf{2 0 0 0} \mathrm{A}-\mathrm{t})$.
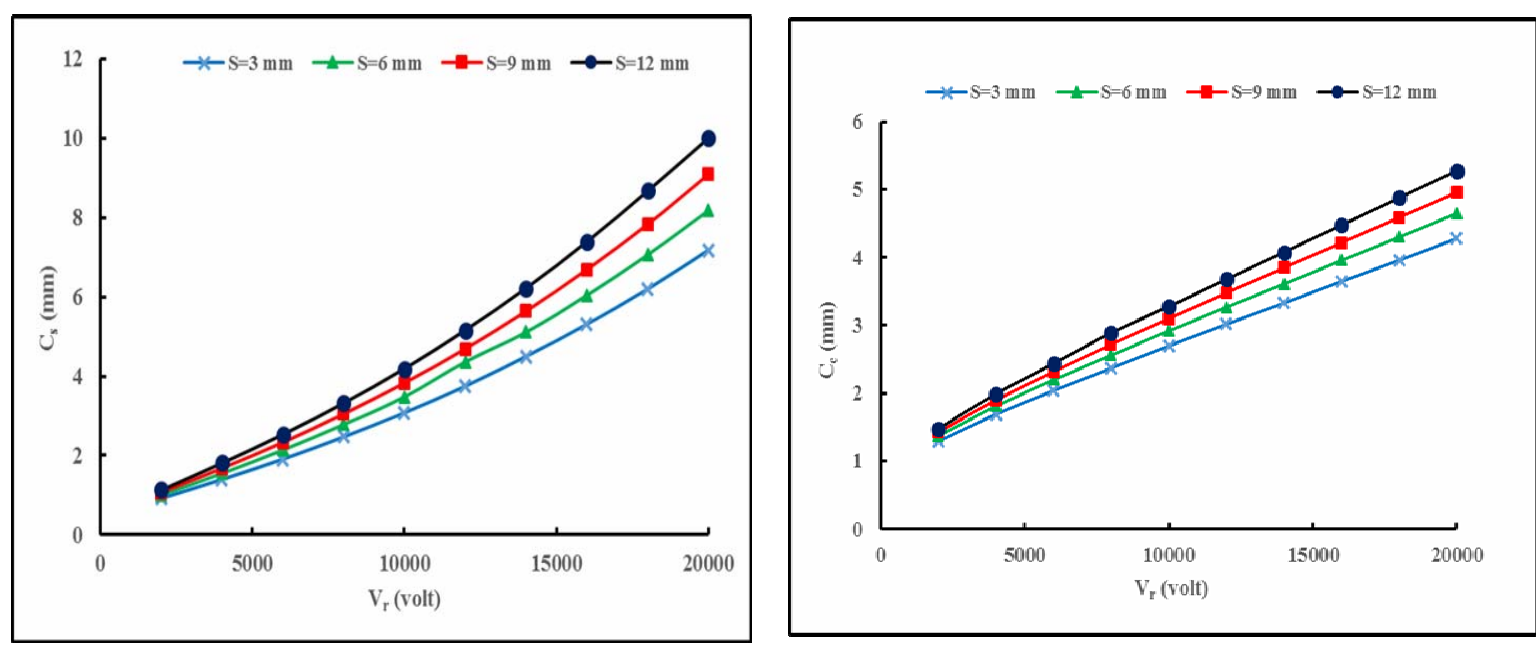

Fig. 9: The variation of the spherical and chromatic aberration coefficients $\left(C_{s}\right.$ and $\left.C_{c}\right)$ as a function of the relativistic accelerating voltage $\left(V_{r}\right)$ of $(S L)$ lens for different values of air gap (S) at the same excitation (NI=2000 A-t). 


\section{The Effect of the Polepiece Bore Diameter on the Snorkel Lens Properties}

In order to evaluate the variation of the polepiece bore diameter $\left(D_{p}\right)$ on the snorkel lens properties, different values of $D_{p}$ have been chosen $\left[D_{p}=(2,4,6\right.$ and 8) mm] and at the air gap $(\mathrm{S}=6 \mathrm{~mm})$ and keeping the other geometrical parameters constant. Fig. (10) shows the effect of the $\left(D_{\mathrm{p}}\right)$ on the axial magnetic flux density distributions $\left(B_{z}\right)$, it is clear that the maximum value of $\left(B_{z}\right)$ increases as the values of the bore diameter decrease.

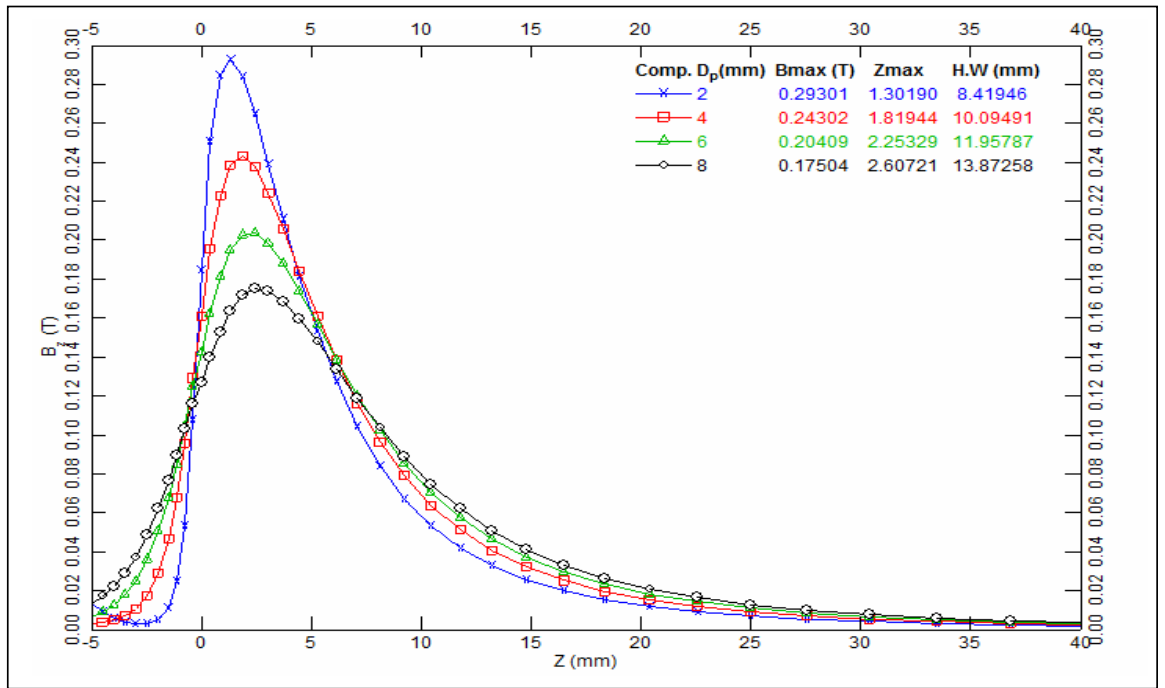

Fig. 10: The axial magnetic flux density distributions $\left(B_{z}\right)$ as a function of the axial distance $(z)$ of $(S L)$ lens for different values of polepiece bore diameter $\left(D_{p}\right)$ at the same excitation $(\mathrm{NI}=\mathbf{2 0 0 0} \mathrm{A}-\mathrm{t})$.

Fig. (11) illustrates the flux lines trajectories for the (SL) lens for different values of $\left(\mathrm{D}_{\mathrm{p}}\right)$ with in the same excitation (NI=2000 A-t). It is clear that the flux lines of the (SL) lens of the value $\left(D_{p}=2 \mathrm{~mm}\right)$ are converge toward the region of polepiece bore diameter compared with the other $\left(D_{p}\right)$ values. Fig. (12) shows the variation of the spherical and chromatic aberration coefficients $\left(\mathrm{C}_{\mathrm{s}}\right.$ and $\left.\mathrm{C}_{\mathrm{c}}\right)$ as a function of the relativistic accelerating voltage $\left(V_{r}\right)$ of the lens $(S L)$ lens at different values of $\left(D_{p}\right)$ with in the same excitation $(\mathrm{NI}=2000 \mathrm{~A}-\mathrm{t})$. It is clear from the figure that $\left(\mathrm{C}_{\mathrm{s}}\right.$ and $\left.\mathrm{C}_{\mathrm{c}}\right)$ are increased by increasing the $\left(V_{r}\right)$, and the lowest values of $\left(C_{s}\right)$ reached at $\left(D_{p}=4 \mathrm{~mm}\right)$, but the lowest values of $\left(C_{c}\right)$ reached at $\left(\mathrm{D}_{\mathrm{p}}=2 \mathrm{~mm}\right)$. 

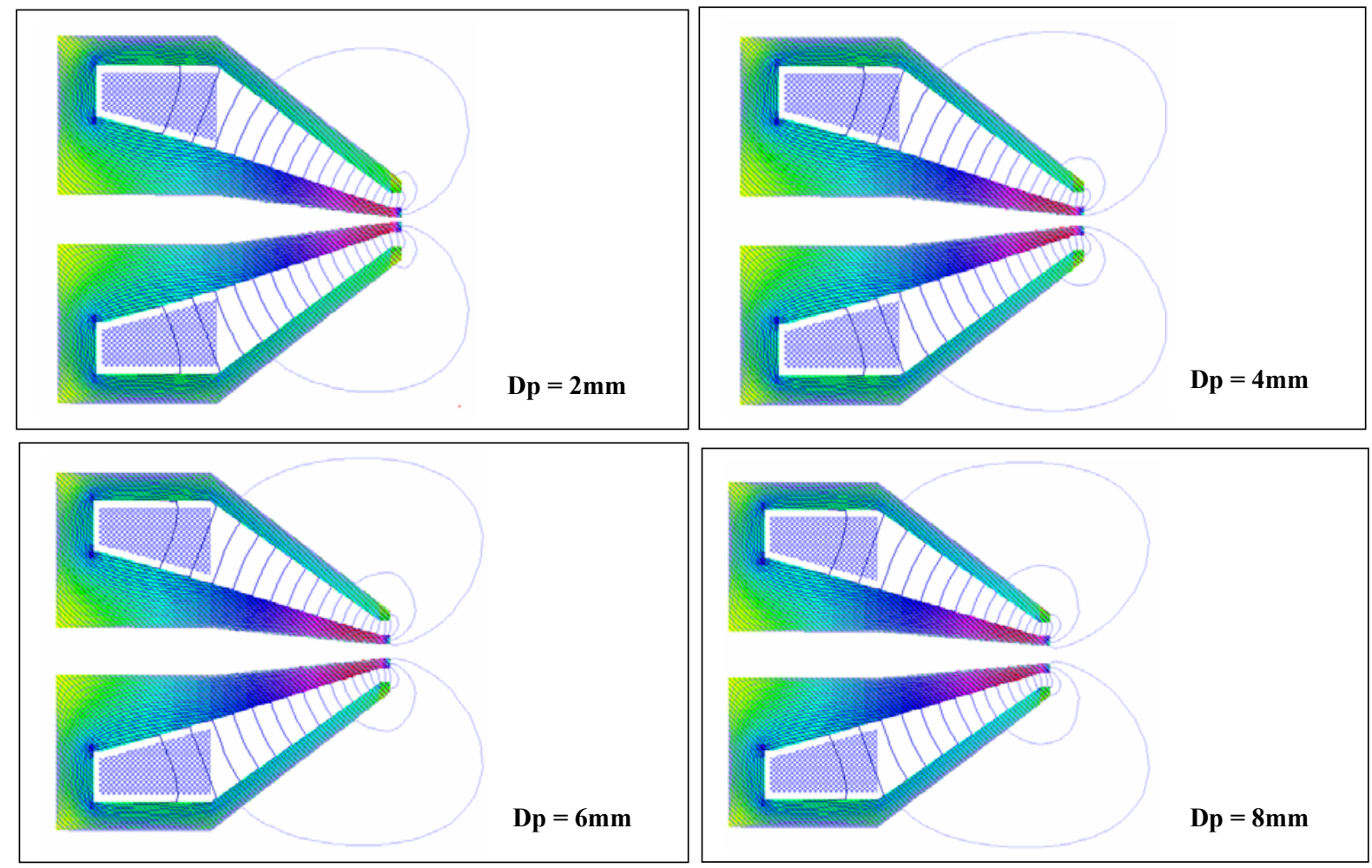

Fig. 11: Flux lines trajectories of lens (SL) for different values of the polepiece bore diameter $\left(D_{p}\right)$ at the same excitation $(N I=2000$ A-t $)$.
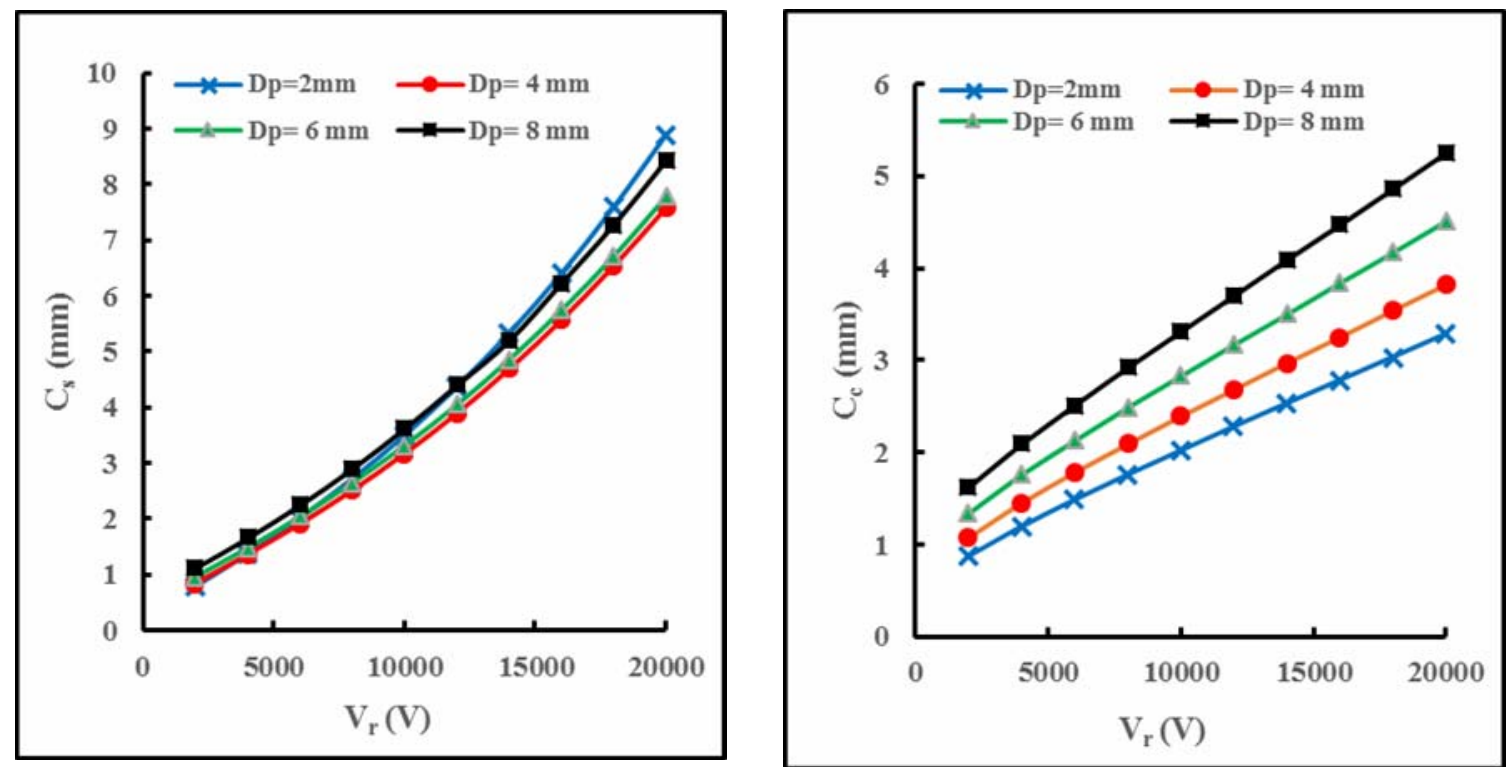

Fig. 12: The variation of the spherical and chromatic aberration coefficients $\left(C_{s}\right.$ and $\left.C_{c}\right)$ as a function of the relativistic accelerating voltage $\left(V_{r}\right)$ of lens (SL) for different values of $\left(D_{p}\right)$ at the same excitation $(\mathrm{NI}=\mathbf{2 0 0 0} \mathrm{A}-\mathrm{t})$. 
Finally, Fig. (13) illustrates the variation of the resolving power $(\delta)$ as a function of both different values of the air gap $(S)$ and the polepiece bore diameter $\left(D_{p}\right)$ of $(S L)$ lens with in same excitation $(\mathrm{NI}=2000 \mathrm{~A}-\mathrm{t})$ and $\left(\mathrm{V}_{\mathrm{r}}=20 \mathrm{KV}\right)$.
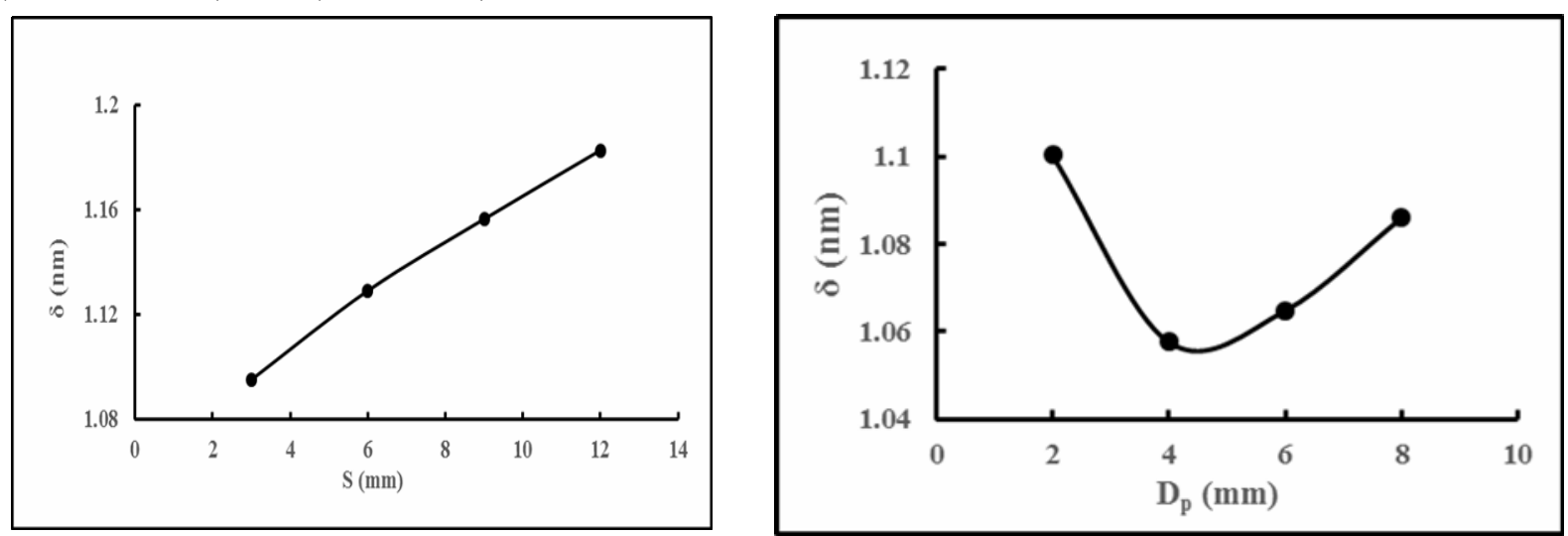

Fig. 13: The variation of the resolving power $(\delta)$ as a function of the (a): air gap (S), (b): polepiece bore diameter $\left(D_{p}\right)$, of $(S L)$ lens at the same excitation $(N I=2000 A-t)$ and $\left(V_{r}=20 K V\right)$.

\section{CONCLUSIONS}

1. It appears that the snorkel lens works at low relativistic accelerating voltage with low spherical and chromatic aberration coefficients at long working distances compared with the pinhole lens. So that this lens is suitable to be used as an objective lens in low voltage scanning electron microscope.

2. It was found that for each geometrical design there exist a specific relativistic accelerating voltage which form an image at a certain plane on the optical axis.

3. The value of the air gap $(S)$ and polepiece bore diameter $\left(D_{p}\right)$ of snorkel lens have influence effect on the axial flux density distribution and on the optical properties, the best properties were reached when $(S=3 \mathrm{~mm})$ and $\left(\mathrm{D}_{\mathrm{p}}=4 \mathrm{~mm}\right)$.

\section{REFERENCES}

Abbass, T.M.; Nasser, B.A. (2012). Study of the objective focal properties for asymmetrical double polepiece magnetic lens. British J. Sci., 6(2), 43-50.

Abd-Hujazie, N.S. (2006). Design of a compound lens (magnetic-electrostatic) for low voltage scanning electron microscope. Ph.D. Thesis, University of Mosul, Iraq.144

Al-Jubbori, M.A.H. (2014). Design and fabrication illumination system in scanning electron microscope. Ph.D. Thesis, University of Mosul, Iraq. 118.

Al-Jumayli, F.A. (2010). Design and fabrication a chroma corrected objective compound lens for low beam energies for scanning electron microscope. Ph.D. Thesis, University of Mosul, Iraq. 127.

Al-Khashab, M.A.; Abbas, I.K. (1991). Optimized polepiece shape for asymmetrical single polepiece magnetic electron lenses. Modeling, Simulation and Control, A. AMSE Press, 35(3), 1-9.

Al-Khashab, M.A.; Ahmad, A.A.H. (2011). The effect of magnetic lens structure insulation on its optical performance. Dirasat, Pure Sci., 38(11), 161-168. 
Al-Khashab, M.A.; Al-Abdullah, A.E. (2006). The magnetization of the single polepiece magnetic electron lens using different coil models. Rafidain J. Sci., 17(2), 37-46.

Al-Khashab, M.A.; Al-Hialey, R.W. (2013). The effect of geometrical shape and position of the coil on optical performance for asymmetrical magnetic lens. Rafidain J. Sci., 24(2), 91-100.

Cleaver, J.R.A. (1980). The choice of polepiece shape and lens operating mode for magnetic objective lenses with saturation polepiece. Optik, 57, 9-34.

EL-Shahat, S.S.; Al Amir, A.S.A.; Hassan, G.S. (2014 a). Studies on the effect of pole piece shape for saturated single pole magnetic lens, Proceedings of the $1^{\text {st }}$ International Conference on New Horizons in Basic and Applied Science, Hurghada - Egypt, 1(1), 290-298.

EL-Shahat, S.S.; Hassan, G.S.; Al Amir, A.S.A. (2014 b). The effect of lens size on performance

Single Pole Magnetic Lens. J. Sci. Research in Physi. and Mathe. Sci., 1(5), 2349-7149.

Goldstein, J.; Newbury, D. E.; Joy, D.C.; Lyman, C.E.; Echlin, P.; Lifshin, E.; Sawyer, L.C.; Michael, J.R. (2003). "Scanning Electron Microscopy and X-Ray Microanalysis". ${ }^{\text {rd }}$ ed. Kluwer Academic / Plenum Publishers. New York.

Hill, R.; Smith, K. (1980). Analysis of the single-pole lens by finite element computation. In Electron Microscopy and Analysis. Edited by Mulvey, T., Inst. Phys. Conf. Ser., 52, (London).

Lencová, B.; Zlámal, J. (2008). A new program for the design of electron microscopes. Sci. Direct, 1, 315-324.

Mulvey, T. (1982). "Unconventional Lens Design in Magnetic Electron Lenses". Ch.5, ed. Hawkes, P.W., Springer-Verlag, Berlin, 359-420.

Mulvey, T.; Newman, C.D. (1973). New electron optical systems for SEM and STEM scanning electron microscopy: Systems and Applications 1973, ed .W.C. Nixon, Inst. Phys. Conf. Ser., 18, 16-21.

Munro, E. (2011). "Munro’s Electron Beam Software MEBS". Report, MEBS Ltd., London SW74AN, England.

Nakagawa, S.; Miyokaum, T.; Noguchi, Y. (1980). Axial magnetic corrected field lens (C-F lens)principle and characteristics, minimizing Cs and Cc. Electron Microscopy, 1(3), 901-909.

Wenxiong, C. (1988). The effect of the polepiece saturation on the electron optical properties of asymmetrical condenser objective lens. Scanning Microscope, 2(3), 1283- 1292. 